\title{
Endometrial immunocompetent cells in proliferative and secretory phase of normal menstrual cycle
}

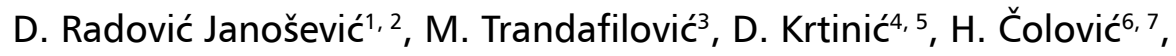 \\ J. Milošević Stevanović1, 2, S. Pop-Trajković Dinićn ${ }^{1,2}$ \\ ${ }^{1}$ Department of Gynaecology and Obstetrics, Faculty of Medicine, University of Niš, Serbia \\ ${ }^{2}$ Gynecology and Obstetrics Clinic, Clinical Centre Niš, Serbia \\ ${ }^{3}$ Department of Anatomy, Faculty of Medicine, University of Niš, Serbia \\ ${ }^{4}$ Department of Pharmacology with Toxicology, Faculty of Medicine, University of Niš, Serbia \\ ${ }^{5}$ Oncology Clinic, Clinical Centre Niš, Serbia \\ ${ }^{6}$ Department of Physical Medicine and Rehabilitation, Faculty of Medicine, University of Niš, Serbia \\ 'Physical Medicine and Rehabilitation Clinic, Clinical Centre, Niš, Serbia
}

[Received: 7 June 2019; Accepted: 11 August 2019]

Background: Menstruation was presented as a result of inflammatory process. The total and relative numbers of the endometrial immunocompetitive cells vary during the different phases of the menstrual cycle. The aim of this morphological study is to make a contribution to understanding different distribution of leukocyte types during proliferative and secretory phase of normal menstrual cycle.

Materials and methods: The study included 40 women $(20$ in proliferative and 20 in secretory phase of the menstrual cycle). Exploratory curettage performed as preoperative preparation due to uterine myomas. Immunophenotyping was performed by immunoalkaline phosphatase (APAAP) using monoclonal antibodies: CD15, CD20, CD30, CD45RO, CD56, CD57 and CD68. The results were statistically analysed using SPSS 20.0 software.

Results: Natural killer (NK) cells are dominant during secretory, and CD45RO $T$ lymphocytes are dominant during proliferative phase of the menstrual cycle. During the secretory phase of menstrual cycle, leukocytes make 30\% of total endometrial cells. NK cells (CD56+ bright subpopulation), activated T lymphocytes, macrophages and $B$ lymphocytes significantly increase in their number during the secretory phase of menstrual cycle.

Conclusions: Significant changes in endometrial leukocyte populations during proliferative and secretory phase of the menstrual cycle are emphasized. Changes in dominance of different leukocyte subpopulations are determined by hormonal and microenvironmental changes in modulatory factors that have not yet been fully explained. (Folia Morphol 2020; 79, 2: 296-302)

Key words: menstrual cycle, endometrium, leukocyte, immune cells, NK cells

\section{INTRODUCTION}

Menstruation is very unusual physiological process specific to some species of animals, including humans. Menstruation was presented as a result of inflammatory process by Finn in 1986 . This hypothesis was based on the characteristics of endometrium

Address for correspondence: D. Radović Janošević, MD, PhD, Assistant Professor, Department of Gynaecology and Obstetrics, Faculty of Medicine, University of Niš, Blvd. Dr Zoran Đinđić 81, 18000 Niš, Serbia, tel: +381 18 4570029, fax: +381 184238770 ,

e-mail: dragana.radosevic.janosevic@medfak.ni.ac.rs 
during the late secretory phase - the presence of the oedema; the influx of migratory cells; the presence of the decidual cells that have some characteristics representative for granulation tissue fibroblasts [10].

The human endometrium is dynamic tissue and its cellular composition changes according to hormonal changes during menstrual cycle. After the menstrual bleeding, the next phase is endometrial reepithelialisation. This process is initiated by stem cells in endometrial glands located in the basalis layer, but also from residual rafts of the luminal epithelium. Mitosis of the stromal fibroblasts and cells in the blood vessel wall leads to the enlargement of the endometrial wall thickness during the proliferative phase. During the next, secretory phase of the menstrual cycle, many endoemetrial cell types' change, but decidualisation of some stromal cells is the most characteristic. In the absence of the pregnancy, endometrial wall becomes reduced in thickness that follows menstrual bleeding. Cellular changes are linked with hormonal changes. The endometrial proliferative phase is stimulated by ovarian follicular oestradiol, but the secretory phase is stimulated by luteal progesterone. As luteolysis begins, oestradiol and progesterone levels fall and premenstrual phase begins. It happens 2 days before menstrual bleeding. The total and relative numbers of the endometrial cells vary during the different phases of the menstrual cycle [19, 20, 24].

It is well known that, so called, "endometrial leukocyte infiltration" happens premenstrually. Precise immunological roles of different leukocyte types during different phases of the menstrual cycle are still under investigation. This type of cells achieves $40 \%$ of stromal cells in some phases of the menstrual cycle [1]. The aim of this morphological study is to make a contribution to understanding different distribution of leukocyte types during proliferative and secretory phase of normal menstrual cycle.

\section{MATERIALS AND METHODS}

This study included 20 patients in the proliferative phase and 20 patients in the secretory phase of the menstrual cycle. The patients aged between 25 and 40 years. Tissue samples were obtained by exploratory curettage due to preoperative preparation. Indication for operative procedure was uterine myoma ( 5 to $10 \mathrm{~cm}$ in size). Menstrual cycle phase was determined by transvaginal ultrasound and based on endometrial morphology, the ovarian follicle or corpus luteum presence.
Curettings were fixed in $10 \%$ formaldehyde solution during 24 hours. Afterward, tissue samples were blocked to paraffin following routine histological procedures. Thin tissue sections $(5 \mu \mathrm{m})$ were stained using the haematoxylin-eosin method. Immunophenotyping was performed using immunoalkaline phosphatase method (APAAP). The APAAP technique is an indirect method which utilises a pre-formed, cyclic enzyme anti-enzyme immune-complex composed of three enzyme molecules (alkaline phosphatase) and two antibody molecules. The technique was visualised by using red dye (Fast Red TR). Antigen retrieval was achieved by proteolytic digestion. The following monoclonal antibodies (Dako-Agilent Technologies, Denmark) were used: CD15 (clone: C3D-1, mouse anti-human antibody, dilution 1:20, marker for leukocytes); CD20 (clone: L26, mouse anti-human antibody, dilution 1:300, marker for B lymphocytes); CD30 (clone: Ber H2, mouse anti-human antibody, dilution 1:200, marker for activated cells); CD45RO (clone: UCHL1, mouse anti-human antibody, dilution 1:400, marker for T lymphocytes); CD56 (clone: 123C3, mouse anti-human antibody, dilution 1:200, marker for natural killer cells - NK cells) and CD57 (clone: TB01, mouse anti-human antibody, dilution 1:200, markers for natural killer cells - NK cells); CD68 (clone: PG-M1, mouse anti-human antibody, dilution 1:200, marker for macrophages). Visualisation of the reaction was performed using New Fuchsin. Positive reaction was visualised as bright red deposits. A cell count was performed under light microscope with $400 \times$ magnification and A100 test system. The number of cells was determined by standard method - at 10 representative high-power fields (10 HPFs).

\section{Statistical analysis}

The results were statistically analysed using SPSS 20.0 software (IBM Corp. Released 2011. IBM SPSS Statistics for Windows, Version 20.0. Armonk, NY: IBM Corp.). Statistical significance was tested by Student's t-test and t-test with method for corrective approximation by Cochran and Cox (for small samples when it was necessary). $P$ values of $<0.05$ were considered statistically significant.

\section{RESULTS}

An average value and percentage of the leukocyte population and average number of cells in the endometrial tissue in the proliferative and in the secretory phase of the menstrual cycle (in $10 \mathrm{HPFs}$ ) is shown 
Table 1. Average number and percentage of leukocytes (CD15 positive cells) and the average total number of cells in the endometrial tissue in different phases of menstrual cycle

\begin{tabular}{lcc}
\hline Menstrual cycle & Leukocytes & Total number of cells \\
\hline Proliferative phase & $97.7 \pm 18.9(6 \%)$ & $1629.8 \pm 303.2^{* *}$ \\
Secretory phase & $116.9 \pm 11.45(30 \%)^{* *}$ & $389.7 \pm 38.17$ \\
\hline
\end{tabular}

**p $<0.001$

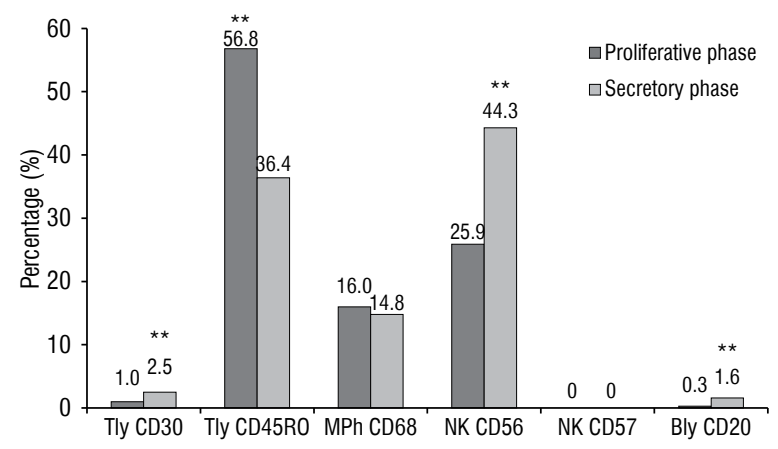

Figure 1. Percentage of the present leukocyte subpopulations, depending on the phase of the menstrual cycle; Tly - T lymphocytes; MPh — macrophages; Bly — B lymphocytes; ${ }^{* *} \mathrm{p}<0.001$.

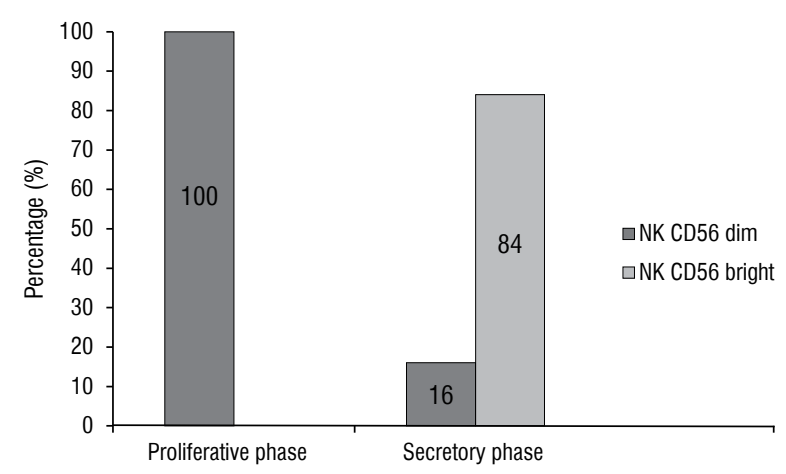

Figure 2. Percentage of NK CD56 positive cells subpopulations in the endometrial tissue in different phases of menstrual cycle.

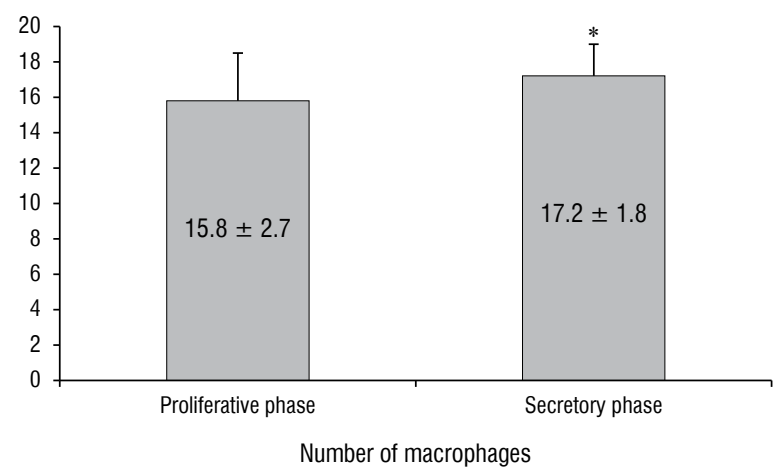

Figure 3. The average number of the macrophages in the endometrial tissue in different phases of menstrual cycle; ${ }^{*} p<0.05$. in the Table 1. There is significantly less number of leukocytes in the proliferative phase in relation to secretory phase $(p<0.001)$.

The number of CD56 positive NK cells was significantly higher in the secretory phase of menstrual cycle $(p<0.001)$. In the endometrial tissue, during the both analysed menstrual cycle phases, CD57 positive NK cells were not noted (Fig. 1).

Two different subsets of CD56 positive NK lymphocytes have been identified in the endometrial tissue - CD56 positive dim and bright NK lymphocytes. The percentage of these immunoreactive subsets has changed depending on the cycle phase. In the proliferative phase only $\mathrm{CD} 56$ positive dim cells were noted, but in the secretory phase CD56 positive bright cells were dominant (Fig. 2).

Average number and percentage of T lymphocyte subpopulations is significantly different between analysed phases of the menstrual cycle (Fig. 1). CD30 positive, activated $\mathrm{T}$ lymphocytes are statistically higher in the secretory, but CD45RO positive T lymphocytes are statistically higher in the proliferative phase of the menstrual cycle $(p<0.001)$. In the both analysed phases, CD45RO positive $T$ lymphocytes were dominant subpopulation.

The average number of macrophages (CD68 positive cells) was significantly higher in the secretory phase ( $p$ < 0.05) (Fig. 3).

The average number and percentage of $B$ lymphocytes (CD20 positive cells) in the endometrial tissue was significantly higher in the secretory phase $(p<0.001)$ (Fig. 1).

Frequency percentage of all analysed subpopulations of leukocytes is given in Figure 1. During secretory and proliferative phases, NK cells and CD45RO $T$ lymphocytes are dominant in the endometrial tissue. NK cells are dominant during secretory, and CD45RO T lymphocytes are dominant during proliferative phase of the menstrual cycle.

Figure 4 represents immunohistochemical staining of T lymphocytes, macrophages, NK cells and $B$ lymphocytes in endometrium during secretory phase of the menstrual cycle.

\section{DISCUSSION}

During the normal menstrual cycle, uterine leukocytes provide immune protection for the uterine mucosa. These cells influence endometrial remodelling, decidualisation, implantation of the embryo or facilitate the process of menstruation. It is not- 


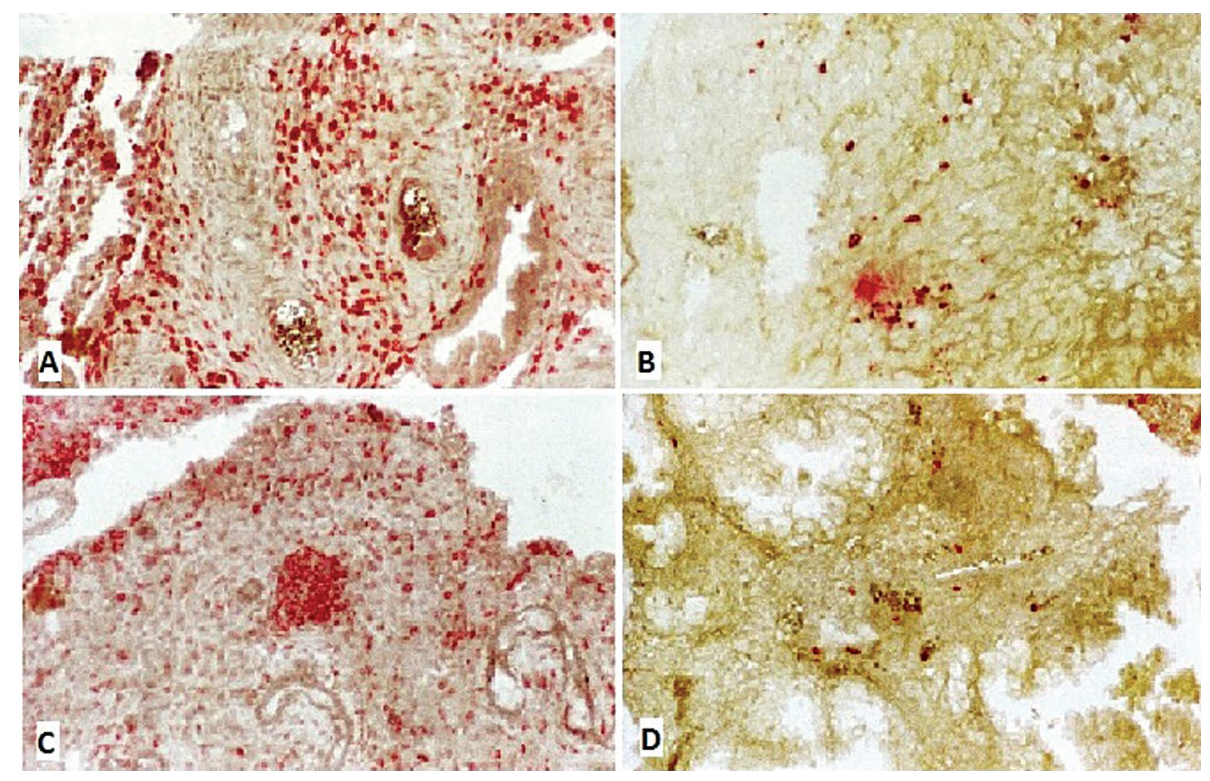

Figure 4. Presentation of the endometrial immunocompetent cells in the secretory phase of the menstrual cycle $(400 \times)$ : A. T lymphocytes (CD45R0 positive cells); B. Macrophages (CD68 positive cells); C. NK cells (CD56 positive cells); D. B lymphocytes (CD20 positive cells).

ed that macrophages, neutrophils and NK cells are engaged in the endometrium during the secretory phase and prepare the tissue for menstruation $[5,22$, 25]. During the late secretory phase, macrophages, eosinophils, neutrophils, granular lymphocytes, B and T lymphocytes and mast cells represent up to $40 \%$ of total endometrial stromal cells [24]. A recent study confirmed this state, but the total number of leukocytes made $30 \%$ of total endometrial cell number in secretory phase. The number of total cells significantly increases in proliferative phase, but percentage of leukocytes significantly increases in secretory phase of the menstrual cycle. Increased number of macrophages and neutrophils produce neutral antimicrobial proteins and provide microbial protection at the time of disrupted epithelial barrier $[16,17]$. It is interesting that mast cells have relatively constant number during the menstrual cycle, but elevated expression of the extracellular tryptase suggests increased activation of these cells. Mast cells release different mediators that induce tissue oedema and activate proteolytic enzymes and matrix metalloproteinases which induce degradation of extracellular matrix [24]. During the menstruation, it is emphasized increased number of $T$ and $B$ cells, macrophages, NK cells and plasma cells in uterine drainage lymph nodes, too. At the same time, the number of stromal cells in the endometrium is increased. This suggests that menstruation is associated with specific adaptive immunological activation [1].
Endometrial NK cells, known as endometrial granular lymphocytes, have different subtypes (CD56+, CD2+/-, CD 38+, CD16-, CD3-) and this type of cells is the most numerous haematopoietic cells in the endometrium [4]. Their number increase in stroma during the secretory phase up to $15 \%$ [24] or $25 \%$ [4] of total cell number. A recent study demonstrated significantly increase in NK cells during secretory phase of the menstrual cycle. NK CD56+ cells made $25.9 \%$ of leukocytes during proliferative, but $44.3 \%$ of leukocytes during secretory phase. NK CD56+ cells have two subsets: NK CD56 dim cells that have high level of CD56 expression ( $90 \%$ of NK cells in peripheral blood) and NK CD56 bright cells that have low level of CD56 expression (10\% of NK cells in peripheral blood) [9]. NK CD56 dim cells show higher level of cytotoxicity and NK CD56 bright cells are source of uterine NK cells and immunomodulatory cytokines [8]. In the recent study, NK CD57+ cells were not noted in endometrium. It was the first difference in comparison with peripheral NK cells. Otherwise, NK CD56 dim cells are NK cells of proliferative and NK CD56 bright cells are NK cells of the secretory phase of the menstrual cycle. Endometrial granular lymphocytes contain perforin, granzime $A, T$ cell intraplasmic antigen and some metalloproteinases that are involved in cell and tissue degradation [18].

Subsets of T cells (CD8+ and CD4+) have a ratio in endometrium inverted in comparison with their ratio in 
the peripheral blood. Endometrial ratio is $66 \%$ of CD8+ $\mathrm{T}$ cells (cytotoxic phenotype) and 33\% CD4+ T cells (helper phenotype). T cells are cytolytically active during the proliferative phase, but this activity decreases in the secretory phase of the menstrual cycle. It is suggested that progesterone can down-regulate this activity [30]. Some previous studies showed that CD8+ T cells are highly activated during the proliferative phase. This activation, that is especially high during the early- and mid-proliferative phase, could be of crucial importance for clearance of potential antigens and residual debris in the uterine cavity. T cell activity decreases due to increasing oestrogen levels prior to ovulation [15]. A recent study emphasized significant increase in total T cells' number during proliferative phase, but significant increase in activated $T$ cells number during secretory phase. This result could be a consequence of unseparated fractions of $T$ cells. During the menstrual cycle, B lymphocytes are noted in low numbers, but perimenstrually these cells are organized in clusters in endometrial stroma [24]. Recent study confirmed B lymphocytes in percentage less than $2 \%$ of total leukocytes during the menstrual cycle. In secretory phase, percentage of $B$ cells is significantly increased in comparison with proliferative phase ( $1.6 \%$ vs. $0.3 \%$ ).

Neutrophils, eosinophils and macrophages are detectable in very small number in normal endometrium during most of the cycle, but perimenstrually, their number increases. The number of neutrophils, as well as macrophages, achieves $6-15 \%$ of total cell number [24]. Interferon gamma is detected in human endometrial intraepithelial neutrophils and this mediator is an activator of macrophages and suggesting an interaction between these types of leukocytes $[11,31]$. Macrophages in the recent study showed increase in absolute number during secretory phase, but in percentage comparison with other immunocompetitive cells, the percentage of macrophages decrease during secretory phase. During menstrual cycle, macrophages made less than $5 \%$ of total cell number. Macrophages are found at sites of active tissue remodelling, as an immune cells of chronic inflammatory lesions [3].

Migratory endometrial leukocytes may influence vascular permeability. Dysregulation of the leukocyte activity and disbalance in its number is reported in women with heavy menstrual bleeding [21]. T regulatory cells have been shown to help to establish allotolerance and successful pregnancy [13]. Elevated levels of activated NK cells and increased cytotoxicity are noted in recurrent pregnancy loss [7, 27].

The number of leukocytes in the endometrium can be regulated in two ways: as a proliferation in situ or as a migratory process from the peripheral circulation. Some human uterine leukocytes, as macrophages, T cells or endometrial lymphocytes, express neither oestrogen nor progesterone receptors, so the effect of these steroid hormones on these types of immune cells could be indirect [18]. It is still under the investigation if immune cells migration from the peripheral circulation to the endometrium is mediated by factors such as chemokines or adhesion molecules. Some monocyte chemotactic proteins are localised in the perivascular cells and show intense immunostaining in the late secretory and proliferative phases of the menstrual cycle. Besides that, these proteins showed wide individual variety in staining [14]. In endometrium, during the late secretory phase, eotaxin is detected in the perivascular cells [32]. It is postulated that chemokines included in the control of immune cells' influx prior to menstruation and their moving to the subepithelial space. In this location, immune cells are capable for appropriate activity [26]. Various adhesion molecules are investigated and it is concluded that their site-specific expression could be related to the distinct distribution of endometrial leukocytes [29]. There are some studies that proved leukocyte proliferation in situ in the late secretory phase. Some cells (CD45+, CD3+, CD11c+, CD56+) express proliferation markers in this period. In vitro studies demonstrated proliferation of CD56+ cells in the presence of the endometrial stromal cells and progesterone $[12,28]$. During the mid- and late-secretory phase, human endometrial and stromal cells reaching the peak of production of interleukin-1 and tumour necrosis factor alpha, as well as some mediators that are steroid-hormone modulated, such as prostaglandins, endothelin, nitric oxide, transforming growth factor beta. All interactions between endometrial immune cells and these modulators are not completely defined, but these factors may have a role in the migration, proliferation and activation of immune cells [24].

Leukocytes have a potential role in contributing to menstruation. Leukocytes produce factors that can directly or indirectly contribute to menstruation. Direct effects are tissue degradation via producing proteolytic enzymes. Indirect effects are evident in the stimulation of adjacent cells to produce other active enzymes, such as plasminogen activator pro- 
duced by macrophages [23, 24, 32]. Besides the role in tissue degradation, leukocytes give a contribution in processes of endometrial reparation. Macrophages produce fibroblast-growth factor, vascular endothelial-growth factor, transforming growth factor alpha and beta, activin beta. Lymphocytes produce fibroblast growth factor and leukocyte-derived growth factor. Tryptase produced by mast cells is mitogen for epithelial cells $[2,6]$.

\section{CONCLUSIONS}

During the secretory phase of menstrual cycle, leukocytes make $30 \%$ of total endometrial cells. NK cells (CD56 + bright subpopulation), activated T lymphocytes, macrophages and $B$ lymphocytes significant increase their number during the secretory phase of menstrual cycle. These changes in dominance of different leukocyte subpopulations could be determined by hormonal and microenvironmental changes in modulatory factors.

\section{Acknowledgements}

This study was supported by the Ministry of Science and Technological Development, Republic of Serbia (Nos 31060 and 41018) and by the Internal Projects of Faculty of Medicine in Niš (Nos 3, 15, 22 and 34).

\section{REFERENCES}

1. Berbic M, Fraser IS. Immunology of normal and abnormal menstruation. Womens Health (Lond). 2013; 9(4): 387-395, doi: 10.2217/whe.13.32, indexed in Pubmed: 23826779.

2. Blotnick S, Peoples GE, Freeman MR, et al. T lymphocytes synthesize and export heparin-binding epidermal growth factor-like growth factor and basic fibroblast growth factor, mitogens for vascular cells and fibroblasts: differential production and release by CD4+ and CD8+ T cells. Proc Natl Acad Sci U S A. 1994; 91 (8): 2890-2894, doi: 10.1073/ pnas.91.8.2890, indexed in Pubmed: 7909156.

3. Bonatz G, Hansmann ML, Buchholz F, et al. Macrophageand lymphocyte-subtypes in the endometrium during different phases of the ovarian cycle. Int J Gynaecol Obstet. 1992; 37(1): 29-36, doi: 10.1016/0020-7292(92)90974-n, indexed in Pubmed: 1346597.

4. Bulmer JN, Morrison L, Longfellow M, et al. Granulated lymphocytes in human endometrium: histochemical and immunohistochemical studies. Hum Reprod. 1991; 6(6): 791-798, doi: 10.1093/oxfordjournals. humrep.a137430, indexed in Pubmed: 1757516.

5. Bulmer JN, Lunny DP, Hagin SV. Immunohistochemical characterization of stromal leucocytes in nonpregnant human endometrium. Am J Reprod Immunol Microbiol. 1988; 17(3): 83-90, doi: 10.1111/j.1600-0897.1988. tb00208.x, indexed in Pubmed: 3264464.
6. Cairns JA, Walls AF. Mast cell tryptase is a mitogen for epithelial cells. Stimulation of IL-8 production and intercellular adhesion molecule-1 expression. J Immunol. 1996; 156(1): 275-283, indexed in Pubmed: 8598474.

7. Coulam C, Roussev R. Correlation of NK cell activation and inhibition markers with NK cytotoxicity among women experiencing immunologic implantation failure after in vitro fertilization and embryo transfer. J Assisted Reprod Genet. 2003; 20(2): 58-62, doi: 10.1023/a:1021736007376, indexed in Pubmed: 12688589.

8. Dietl J, Hönig A, Kämmerer U, et al. Natural killer cells and dendritic cells at the human feto-maternal interface: an effective cooperation? Placenta. 2006; 27(4-5): 341-347, doi: 10.1016/j. placenta.2005.05.001, indexed in Pubmed: 16023204.

9. Dosiou C, Giudice LC. Natural killer cells in pregnancy and recurrent pregnancy loss: endocrine and immunologic perspectives. Endocr Rev. 2005; 26(1): 44-62, doi: 10.1210/ er.2003-0021, indexed in Pubmed: 15689572.

10. Finn CA. Implantation, menstruation and inflammation. Biol Rev Camb Philos Soc. 1986; 61(4): 313-328, doi: 10.1111/j.1469-185x.1986.tb00657.x, indexed in Pubmed: 3542071.

11. Haddad EK, Duclos AJ, Antecka E, et al. Role of interferon-gamma in the priming of decidual macrophages for nitric oxide production and early pregnancy loss. Cell Immunol. 1997; 181(1): 68-75, doi: 10.1006/cimm.1997.1199, indexed in Pubmed: 9344498.

12. Inoue T, Kanzaki H, Imai K, et al. Progesterone stimulates the induction of human endometrial CD56+ lymphocytes in an in vitro culture system. J Clin Endocrinol Metab. 1996; 81(4): 1502-1507, doi: 10.1210/jcem.81.4.8636358, indexed in Pubmed: 8636358.

13. Jasper MJ, Tremellen KP, Robertson SA. Primary unexplained infertility is associated with reduced expression of the T-regulatory cell transcription factor Foxp3 in endometrial tissue. Mol Hum Reprod. 2006; 12(5): 301-308, doi: 10.1093/molehr/gal032, indexed in Pubmed: 16574699.

14. Jones RL, Kelly RW, Critchley HO. Chemokine and cyclooxygenase-2 expression in human endometrium coincides with leukocyte accumulation. Human Reprod. 1997; 12(6): 1300-1306, doi: 10.1093/humrep/12.6.1300.

15. Khan KN, Kitajima M, Hiraki K, et al. Escherichia coli contamination of menstrual blood and effect of bacterial endotoxin on endometriosis. Fertil Steril. 2010; 94(7): 2860-3.e1, doi: 10.1016/j.fertnstert.2010.04.053, indexed in Pubmed: 20627244.

16. King AE, Critchley HOD, Kelly RW. Innate immune defences in the human endometrium. Reprod Biol Endocrinol. 2003; 1: 116, doi: 10.1186/1477-7827-1-116, indexed in Pubmed: 14641912.

17. King $A E$, Fleming $D C$, Critchley HOD, et al. Regulation of natural antibiotic expression by inflammatory mediators and mimics of infection in human endometrial epithelial cells. Mol Hum Reprod. 2002; 8(4): 341-349, doi: 10.1093/ molehr/8.4.341, indexed in Pubmed: 11912282.

18. King A, Wooding P, Gardner L, et al. Expression of perforin, granzyme $A$ and TIA-1 by human uterine CD56+ NK cells implies they are activated and capable of effector functions. Hum Reprod. 1993; 8(12): 2061-2067, doi: 10.1093/oxfordjournals.humrep.a137982, indexed in Pubmed: 7512092. 
19. Klentzeris LD, Bulmer JN, Warren A, et al. Endometrial lymphoid tissue in the timed endometrial biopsy: morphometric and immunohistochemical aspects. Am J Obstet Gynecol. 1992; 167(3): 667-674, doi: 10.1016/ s0002-9378(11)91568-3, indexed in Pubmed: 1530020.

20. Loke YW, King A. Human Implantation. Cell Biology and Immunology. Cambridge University Press, Cambridge: UK 1995.

21. Paton RC, Tindall H, Zuzel M, Fraser IS, Webb FTG. et al.. Haemostatic mechanisms in the normal endometrium and endometrium exposed to contraceptive steroids. In: Diczfalusy E. (Ed.) Endometrial Bleeding and Steroidal Contraception. Pitman Press, Bath, UK 1980: 325-341.

22. Salamonsen LA, Lathbury L. Endometrial leukocytes and menstruation. Hum Reprod Update. 2000; 6(1): 16-27, doi: 10.1093/humupd/6.1.16, indexed in Pubmed: 10711826.

23. Salamonsen LA, Woolley DE. Matrix metalloproteinases in normal menstruation. Human Reprod. 1996; 11(suppl 2): 124-133, doi: 10.1093/humrep/11.suppl_2.124, indexed in Pubmed: 8982754.

24. Salamonsen LA, Woolley DE. Menstruation: induction by matrix metalloproteinases and inflammatory cells. J Reprod Immunol. 1999; 44(1-2): 1-27, doi: 10.1016/ s0165-0378(99)00002-9, indexed in Pubmed: 10530758.

25. Salamonsen L, Zhang J, Brasted M. Leukocyte networks and human endometrial remodelling. J Reprod Immunol. 2002; 57(1-2): 95-108, doi: 10.1016/s01650378(02)00011-6, indexed in Pubmed: 12385836.

26. Schall TJ, Bacon KB. Chemokines, leukocyte trafficking, and inflammation. Curr Opin Immunol. 1994; 6(6): 865-873, doi: 10.1016/0952-7915(94)90006-x, indexed in Pubmed: 7710711.

27. Szekeres-Bartho J, Barakonyi A, Polgar B, et al. The role of gamma/delta T cells in progesterone-mediated immunomodulation during pregnancy: a review. Am J Reprod Immunol. 1999; 42(1): 44-48, doi: 10.1111/j.16000897.1999.tb00464.x, indexed in Pubmed: 10429766.

28. Tabibzadeh S. Proliferative activity of lymphoid cells in human endometrium throughout the menstrual cycle. J Clin Endocrinol Metab. 1990; 70(2): 437-443, doi: 10.1210/ jcem-70-2-437, indexed in Pubmed: 1688866.

29. Tabibzadeh S, Kong QF, Babaknia A. Expression of adhesion molecules in human endometrial vasculature throughout the menstrual cycle. J Clin Endocrinol Metab. 1994; 79(4): 1024-1032, doi: 10.1210/jcem.79.4.7962270, indexed in Pubmed: 7962270.

30. White HD, Crassi KM, Givan AL, et al. CD3+CD8+ CTL activity within the human female reproductive tract: influence of stage of the menstrual cycle and menopause. $\mathrm{J}$ Immunol. 1997; 158(6): 3017-3027, indexed in Pubmed: 9058841.

31. Yeaman GR, Collins JE, Currie JK, et al. IFN-gamma is produced by polymorphonuclear neutrophils in human uterine endometrium and by cultured peripheral blood polymorphonuclear neutrophils. J Immunol. 1998; 160(10): 5145-5153, indexed in Pubmed: 9590267.

32. Zhang J, Lathbury U, Salamonsen LA. Expression of the chemokine eotaxin and its receptor, CCR3, in human endometrium. Biol Reprod. 2000; 62(2): 404-411, doi: 10.1095/ biolreprod62.2.404, indexed in Pubmed: 10642580. 